\title{
Interannual variations of blockings in the Southern Hemisphere and their energetics
}

\author{
Rosa de Fátima Cruz Marques and V. Brahmananda Rao \\ Instituto Nacional de Pesquisas Espaciais (INPE), São José dos Campos, São Paulo, Brazil
}

\begin{abstract}
Seasonal and interannual variations of blocking in the Southern Hemisphere (SH) are discussed using 25 years of NCEP and 14 years of ECMWF data sets. Both the data sets show that the highest blocking frequency occurs near New Zealand, but ECMWF data seem to show higher blocking frequency. There are large interannual variations in blocking frequency over east and west Pacific, the principal regions of blocking in the SH. Linear correlation coefficients (CC) between the frequency of blocking and the Southern Oscillation Index show mostly negative values, indicating that blocking increases during the El Niño events. A significant value (at $95 \%$ level) of $\mathrm{CC}$ is found only for the west Pacific in the austral autumn season. Two sets of three high and low blocking frequency years are selected to explore the possible causes for interannual variations. Mak's energy equations are used to examine the differences in energetics. To maximize the differences, two extreme years of blocking, a year of high blocking frequency, 1984, and a year of low blocking frequency, 1990, are considered. It is found that the generation of kinetic energy by barotropic processes on intraseasonal timescales is higher in 1984 than in 1990. This shows that the configuration of seasonal mean (deformation) field supports higher incidence of blocking in 1984 than in 1990.
\end{abstract}

\section{Introduction}

The blocking phenomenon in the atmosphere has been extensively investigated since the early studies of Elliot and Smith [1949] and Rex [1950a, b]. The most significant feature common to these studies is that normal passage of smaller-scale baroclinic weather systems is obstructed and hence the name "blocking." Because of its importance in weather-related human activities such as agriculture, extended range forecasting of blocking situation has been attempted. Despite several advances in operational medium-range weather forecasting, Tibaldi and Molteni [1990] and Tibaldi et al. [1994] have shown that forecasting the onset of blocking events by the European Centre for Medium-Range Weather Forecasts (ECMWF) model is, in general, a difficult task. However, if the integration starts from an already blocked initial condition, the model performance improves. The situation in the Southern Hemisphere $(\mathrm{SH})$ is even worse because of poor data coverage that introduces large initial errors. A good knowledge of observed aspects of blocking in the SH seems to be desirable before an attempt at numerical forecasting is made. Also, observational studies of blocking might help in improving parameterizations in Numerical Weather Prediction models.

There have been several observational studies of blocking in the Northern Hemisphere (NH) [e.g., Rex, 1950a, b; Treidl et al., 1981; Lejenäs and Okland, 1983; Dole, 1989], similar studies for the SH are smaller in number. Van Loon [1956] used 5 years of synoptic charts to study blocking in the SH. Taljaard [1972] described synoptic characteristics of blocking anticyclones in the SH. Blocking in the austral-Asian region has been documented by Wright [1974] and Baines [1983]. Coughlan [1983] compared blocking in the two hemispheres. Lejenäs [1984] used 8 years of $500 \mathrm{hPa}$ geopotential height analyses and

Copyright 2000 by the American Geophysical Union.

Paper number 1999JD901066.

0148-0227/00/1999JD901066\$09.00 discussed blocking in the SH. Trenberth and Mo [1985], using about 8 years of data, found that the principal location of blocking in the $\mathrm{SH}$ is the New Zealand sector and that blocking occurs through a local enhancement of the climatological split in the mean westerlies. Blocking was also noted to occur over the southeast region of South America and the southern Indian Ocean. Berbery and Núñez [1989] made an observational and numerical study of blocking episodes near South America. They concluded that blocking episodes can result from a local resonance between forced Rossby waves generated by the Andes Mountains and an upstream forcing, as suggested by Kalnay-Rivas and Merkine [1981]. Rutllant and Fuenzalida [1991] found a distinct region of blocking over the SE Pacific, and they presented evidence to show that blocking increases during warm events (EI Niño). In a recent study, Sinclair [1996] used 10 years of ECMWF analyses during 1980-1989 to obtain a climatology for blocking in the SH. Blocking episodes were identified as persistent highs having central pressures exceeding the time averaged, mean sea level pressures (MSLP) by more than $20 \mathrm{hPa}$ and also as persistent positive MSLP anomalies. Sinclair [1996] found that long-lasting, quasi-stationary intense blocks occur in two regions of the South Pacific: east of New Zealand and southwest of South America. The latter region of blocking was not found in the earlier studies, probably because of poor data coverage. Renwick [1998] used 16 years (1980-1995) of ECMWF data and examined the connection between blocking and El Niño-Southern Oscillation (ENSO). He found that the number of days of blocking tends to increase, on average, during the warm phase of the ENSO cycle, particularly over the southeast Pacific during the austral spring and summer. For Northern Hemisphere, Renwick and Wallace [1996] found a statistically significant relationship between ENSO variability and frequency of blocking events over the Alaskan region, such that blocking is suppressed during the warm phase of ENSO.

The purpose of the present paper is to study the interannual 
variation of blocking in the SH using 14 years (1980-1993) of ECMWF and 25 years (1973-1997) of NCEP (National Centers for Environmental Prediction) data. To our knowledge this is the first study in which 25 years of daily data have been used to analyze blocking in the $\mathrm{SH}$; nine more years of data will be used in comparison with the 16 years (1980-1995) of climatology of Renwick [1998].

Mechanisms responsible for the interannual variations of blocking are not well documented and understood. One source of interannual variability in blocking flows is the variations in the tropical sea surface temperature (SST) exemplified by El Niño-La Niña phenomenon. Namais [1986] and von Storch [1987] suggested that during El-Niño-type forcing, the extratropical low-frequency variability is smaller than during La Niña forcing, implicitly implying less development of blocking flows during El Niño winters. Chen and Van den Dool [1997] noted that blocking flows develop twice as much over the North Pacific during La Niña than during El Niño winters. They noted that the high-frequency eddies (1-7 days) during La Niña events are more effective in maintaining blocking flows, thus supporting the Shutts [1983] eddy-straining mechanism. Shutts proposed that the high-frequency transient eddies are deformed systematically by the large-scale ambient flows in such a way that they feed back to decelerate the westerlies and help to form and maintain the blocking flow [Shutts, 1983; Trenberth, 1986]. In the SH, Rutllant and Fuenzalida [1991] and Renwick [1998] found a connection between the occurrence of blocking and ENSO. However, in both of these studies they used ECMWF data, which underwent several changes in the model physical processes during the period of data they analyzed. These changes may introduce false interannual variations. However, NCEP reanalysis [Kalnay et al., 1996] data are devoid of this problem and so particularly suitable for the study of interannual variations. In the present study, these data for 25 years (1973-1997) are used in addition to the 14 years (1980-1993) of the ECMWF data. The study with both of these data will permit a comparison of blocking frequency obtained with them.

Mak [1991] developed energy equations to study the blocking flows. Mak evaluated the contribution from three temporal scale interaction (seasonal, intraseasonal, and high-frequency components) to the episodal average local energetics of the block. The synoptic eddy-straining mechanism proposed by Shutts [1983] is mainfested in three energetic terms. However, the conversion term between the seasonal and the intraseasonal components is found to be largest. In the present study we use Mak's energy equations to examine the energy exchange processes during years of extreme (low and high) blocking frequency. Such a study might indicate the changes in the atmospheric process responsible for the interannual differences in the blocking frequency.

\section{Data and Method of Analysis}

In the present study we use 14 years (1980-1993) of ECMWF data at 1200 UTC. The ECMWF analyses were produced by a data assimilation system run as an intermittent 6 hour analyses-initialization-forecast cycle. A review of this modern data assimilation was given by Bengtsson [1991]. A 6 hour forecast from the previous initialized analysis provides the first guess. The ECMWF analyses have undergone some changes. Linear normal mode initialization was introduced in September 1982 and a diurnal cycle of radiation was intro- duced in 1984. For further details about ECMWF data, see Trenberth and Olson [1988]. We use geopotential height $(Z)$, the horizontal velocity $(u, v)$ fields, the vertical $P$-velocity $(\omega)$ field, and temperature field $(T)$. Two months (January and February 1984) of data were missing. The lack of these two months of data was taken into consideration in obtaining the blocking frequency.

In addition to ECMWF data we use NCEP/NCAR (National Centers for Environmental Prediction/National Center for Atmospheric Research) reanalysis data for 25 years (19731997). We use daily geopotential height $(Z)$ at $500 \mathrm{hPa}$. We propose to compare the blocking frequency obtained from both data sources. A detailed description of the NCEP assimilation systems and output were given by Kalnay et al. [1996]. In addition, we obtained the Southern Oscillation Index (SOI) data from Internet (http://rs600.cru.uea.ac.uk/cru/data/ soi.htm). The method used to calculate the SOI is due to Ropelewski and Jones [1987]. The SOI is defined as the normalized pressure difference between Tahiti and Darwin. The SOI data are used to find the connection between ENSO and blocking.

In this study we used a modified method developed by Lejenäs and Okland [1983] and Lejenäs [1984] to identify blocking in the SH. Just as in the work of Lejenäs and Madden [1992], the data were subjected to a Fourier analysis along each latitude, and the first 18 zonal harmonics were retained. The resulting geopotential height at a given latitude was obtained by

$$
Z(\lambda)_{l, j}=[Z]_{l, j}+\sum_{k=1}^{18}\left[a_{k, l, j} \cos (k \lambda)+b_{k, l, j} \sin (k \lambda)\right]
$$

where $\lambda$ is the longitude, and $k$ is the zonal wave number. The first term on the right-hand side of (1) is the zonal mean, and the subscripts $i$ and $j$ represent data from the $i$ th year and $j$ th day.

In the present study we used a blocking index, which is a modified version of that suggested by Lejenäs [1984]. To include occurrence of blocking at latitudes higher than $50^{\circ} \mathrm{S}$, the Lejenäs index is used for three different latitudes.

$$
\begin{aligned}
& I\left(\lambda_{1}\right)=Z_{35 s}(\lambda)-Z_{50 s}(\lambda), \\
& I\left(\lambda_{2}\right)=Z_{35 s}(\lambda)-Z_{55 s}(\lambda), \\
& I\left(\lambda_{3}\right)=Z_{40 s}(\lambda)-Z_{60 s}(\lambda) .
\end{aligned}
$$

The blocking situation should satisfy that mean in $30^{\circ}$ longitudes $([I(\lambda-10)+I(\lambda)+I(\lambda+10)] / 3)$ should be less than zero at one of three cases of (2). These criteria are sufficient to define a local (in time and space) blocking pattern. However, a true synoptic blocking requires a certain time persistence of the event. Thus a further time requirement has to be added to the sector-blocking definition, which is as follows: When two successive days are considered blocked by the index in a sector and are followed by a nonblocked day and then by two more successive blocked days, the entire event is considered as a 5 day block (implicitly assuming that the failure was due to an index failure). A similar criterion is applied in the case of a single nonblocked day preceded (followed) by four blocked days and followed (preceded) by a single blocked day. In addition, all the blocked episodes less than four consecutive days of duration are excluded in the subsequent analysis. These criteria are similar to those used by D'Andrea et al. [1998] for the Northern Hemisphere blocking identified in 15 atmospheric general circulation models. 
In addition to the above criterion, a simple Lejenäs [1984] criterion, i.e., no time duration limit, is also adapted, and only the first index $\left(I\left(\lambda_{1}\right)\right)$ is used. This will permit to make a comparison of blocking in the SH identified by these two methods, particularly the change of the latitude limits. Hereinafter, this method is referred to as method 2 while the earlier one as method 1 .

In section 3, results are presented in terms of the number of blocks and number of blocking days as a percentage of the period (number of days) considered. For example, $2 \%$ in any given month would mean $30 \times 14 \times 0.02 \cong 8$ cases.

To analyze the energetics of the blocking situation, we use the methodology developed by Mak [1991]. We use his notation. Here we shall briefly illustrate the method. For details the reader is referred to Mak's paper. Each meteorological variable, $\xi=z, u, v, \omega$ or $T$ at each grid point is partitioned into three parts, a seasonal component $(0)$, an intraseasonal component (1), and a high-frequency component (2).

$$
\xi=\xi_{0}+\xi_{1}+\xi_{2}
$$

The three operators in time that would achieve partioning into three components are given by

$$
L_{n}\{\xi\}=\xi_{n} \quad(n=0,1,2) .
$$

These components are obtained by two filters. The first filter (zero component) is 61 day running-mean (denoted by an overbar). The second filter is a 7 day running-mean (denoted by a circumflex). The difference between the two gives the intraseasonal (1) component and the difference between the original series and the 7 day running-mean gives the highfrequency component (2).

$$
\begin{gathered}
L_{0}\{\xi\}=\bar{\xi}=\xi_{0}, \\
L_{1}\{\xi\}=\hat{\xi}-\bar{\xi}=\xi_{1}, \\
L_{2}\{\xi\}=\xi-\hat{\xi}=\xi_{2} .
\end{gathered}
$$

Applying the $L_{1}$ operation to the horizontal momentum equation (neglecting vertical advection of momentum) gives

$$
\begin{gathered}
\frac{\partial}{\partial t} \overrightarrow{\mathrm{V}}_{1}=\overrightarrow{\mathrm{A}}_{0,0}+\overrightarrow{\mathrm{A}}_{0,1}+\overrightarrow{\mathrm{A}}_{0,2}+\overrightarrow{\mathrm{A}}_{1,1}+\overrightarrow{\mathrm{A}}_{2,2}+\overrightarrow{\mathrm{A}}_{1,2}-\nabla \Phi_{1} \\
-f \overrightarrow{\mathrm{k} x} \overrightarrow{\mathrm{V}}_{1}+\overrightarrow{\mathrm{F}}_{1}, \\
\vec{A}_{0,0}=-L_{1}\left\{\left(\overrightarrow{\mathrm{V}}_{0} \cdot \nabla\right) \overrightarrow{\mathrm{V}}_{0}\right\}, \\
\vec{A}_{0,1}=-L_{1}\left\{\left(\overrightarrow{\mathrm{V}}_{0} \cdot \nabla\right) \overrightarrow{\mathrm{V}}_{1}+\left(\overrightarrow{\mathrm{V}}_{1} \cdot \nabla\right) \overrightarrow{\mathrm{V}}_{0}\right\}, \\
\vec{A}_{0,2}=-L_{1}\left\{\left(\overrightarrow{\mathrm{V}}_{0} \cdot \nabla\right) \overrightarrow{\mathrm{V}}_{2}+\left(\overrightarrow{\mathrm{V}}_{2} \cdot \nabla\right) \overrightarrow{\mathrm{V}}_{0}\right\}, \\
\vec{A}_{1,1}=-L_{1}\left\{\left(\overrightarrow{\mathrm{V}}_{1} \cdot \nabla\right) \overrightarrow{\mathrm{V}}_{1}\right\}, \\
\vec{A}_{2,2}=-L_{1}\left\{\left(\overrightarrow{\mathrm{V}}_{2} \cdot \nabla\right) \overrightarrow{\mathrm{V}}_{2}\right\}, \\
\vec{A}_{1,2}=-L_{1}\left\{\left(\overrightarrow{\mathrm{V}}_{1} \cdot \nabla\right) \overrightarrow{\mathrm{V}}_{2}+\left(\overrightarrow{\mathrm{V}}_{2} \cdot \nabla\right) \overrightarrow{\mathrm{V}}_{1}\right\} .
\end{gathered}
$$

In this analysis, $\vec{A}_{0,0}$ and $\vec{A}_{0,2}$ are identically zero by definition, since $\vec{V}_{0}$ is approximated by a seasonal mean. Thus (6) reduces to

$\frac{\partial}{\partial t} \overrightarrow{\mathrm{V}}_{1}=\overrightarrow{\mathrm{A}}_{0,1}+\overrightarrow{\mathrm{A}}_{1,1}+\overrightarrow{\mathrm{A}}_{2,2}+\overrightarrow{\mathrm{A}}_{1,2}-\boldsymbol{\nabla} \boldsymbol{\Phi}_{1}-f \overrightarrow{\mathrm{k}} x \overrightarrow{\mathrm{V}}_{1}+\overrightarrow{\mathrm{F}}_{1}$.

By taking the scalar product of (8) with $\vec{V}_{1}$ and taking the average of each resulting term over the austral winter (June,
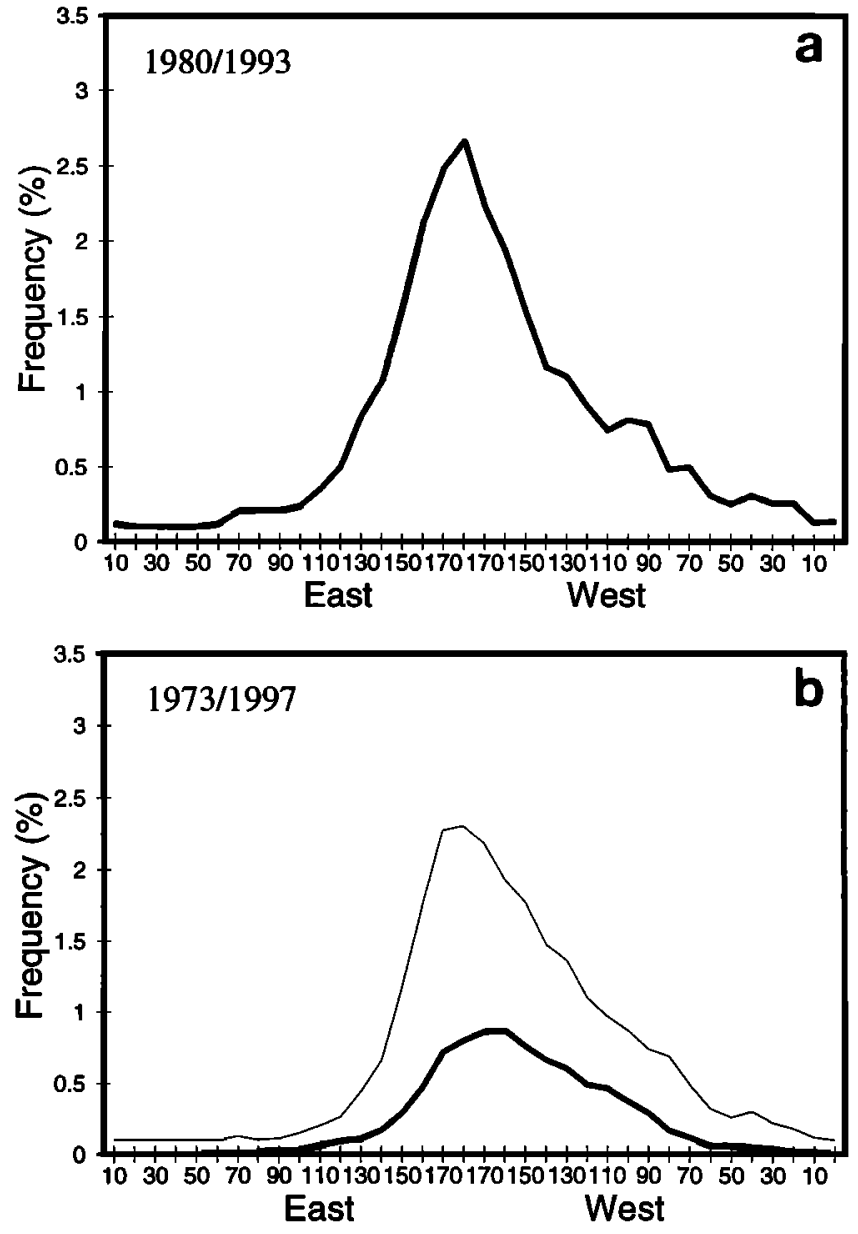

Figure 1. Distribution of blocking frequency as a function of longitude for (a) 14 years (1980-1993), European Centre for Medium-Range Weather Forecasts (ECMWF) data and (b) 25 years (1973-1997), National Centers for Environmental Prediction (NCEP) data: method 1 (thick line), method 2 (thin line).

July, and August), we obtain the equation that governs the kinetic energy of the winter intraseasonal component

$$
\begin{aligned}
\frac{\partial}{\partial t} \overline{K_{1}}= & \overline{\overrightarrow{\mathrm{V}}_{1} \cdot \overrightarrow{\mathrm{A}}_{0,1}}+\overline{\overrightarrow{\mathrm{V}}_{1} \cdot \overrightarrow{\mathrm{A}}_{1,1}}+\overline{\overrightarrow{\mathrm{V}}_{1} \cdot \overrightarrow{\mathrm{A}}_{2,2}}+\overline{\overrightarrow{\mathrm{V}}_{1} \cdot \overrightarrow{\mathrm{A}}_{1,2}} \\
& -\overline{\overrightarrow{\mathrm{V}}_{1} \cdot \nabla \Phi_{1}}+\overline{\overrightarrow{\mathrm{V}}_{1} \cdot \overrightarrow{\mathrm{F}}_{1}} .
\end{aligned}
$$

An overbar represents the average over the winter period. The fifth term on the right-hand side of (9) represents the contribution by the pressure-gradient force. This term may be written in a form representing a conversion between kinetic and potential energy. The last term on the right-hand side of (9) is a measure of frictional dissipation and is evaluated here as a residual by assuming the time tendency term in (9) is zero.

The equation for the time change of available potential energy is given by

$$
\begin{aligned}
\frac{\partial}{\partial t} \overline{\overrightarrow{\mathrm{P}}_{1}}= & \overline{\theta_{1} B_{0,1}}+\overline{\theta_{1} B_{1,1}}+\overline{\theta_{1} B_{2,2}}+\overline{\theta_{1} B_{1,2}}+\overline{R \omega_{1} \theta_{1}} \\
& +\frac{R}{-\partial \Theta / \partial p} \overline{\theta_{1} Q_{1}},
\end{aligned}
$$



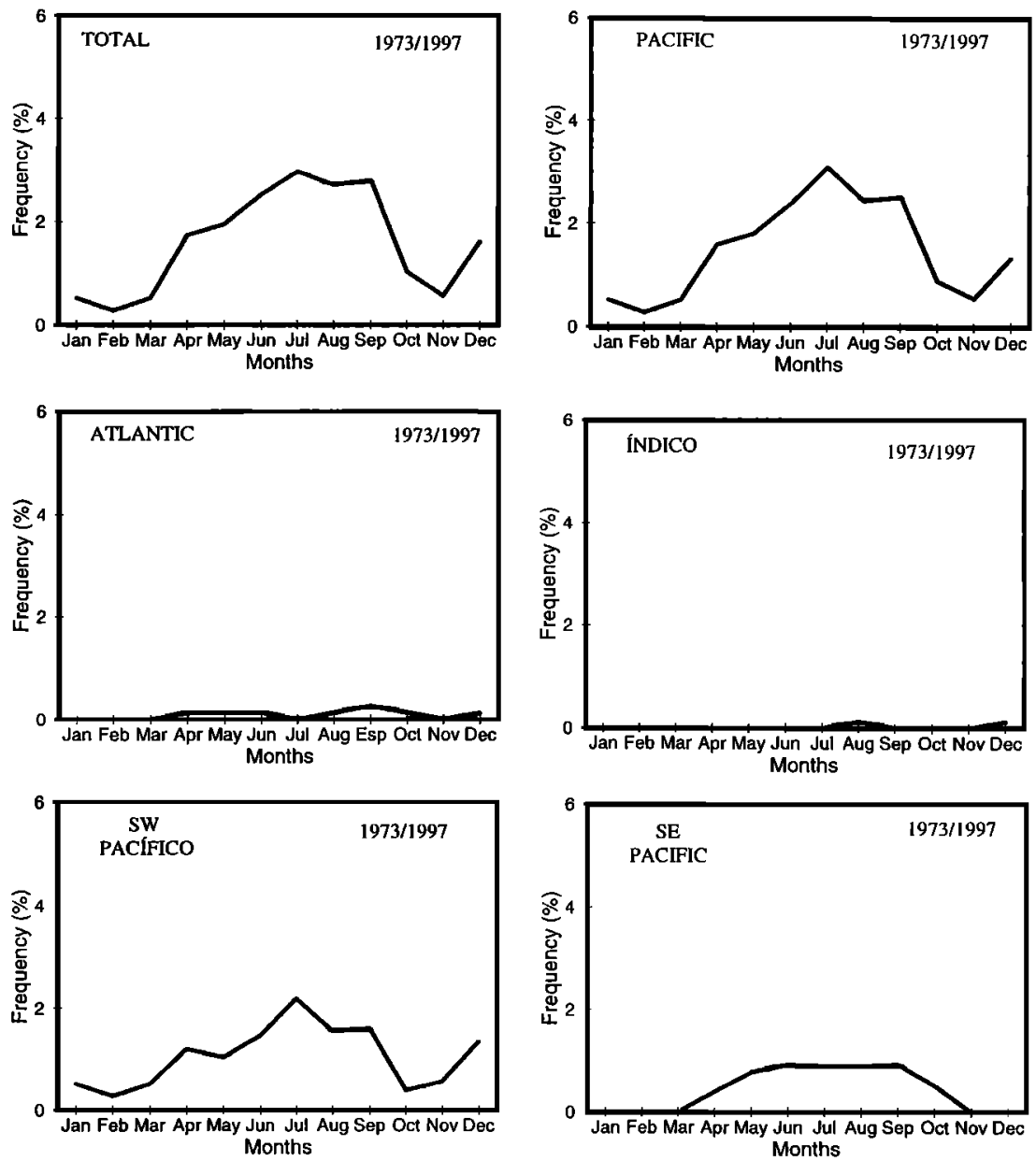

Figure 2. Monthly variation of blocking frequency in NCEP data for the entire Southern Hemisphere (SH) and for the Pacific, Atlantic, and Indian Oceans and southwest, southeast Pacific separately.

where $P_{1}=R \theta_{1}^{2} /(2(-\partial \Theta / \partial P))$ is the available potential energy of the one component associated with the block. In (10), $\theta$ is the potential temperature, $\Theta$ is the domain-averaged potential temperature, $Q$ is the diabatic heating rate in degrees per unit time, and $\omega$ is the $p$-vertical velocity. The explicit forms of the first four terms on the right-hand side are

$$
\begin{gathered}
\theta_{1} B_{0,1}=\left(\frac{R \theta_{1}}{\partial \Theta / \partial p}\right) L_{1}\left\{\left(\overrightarrow{\mathrm{V}}_{0} \cdot \nabla\right) \theta_{1}+\left(\overrightarrow{\mathrm{V}}_{1} \cdot \nabla\right) \theta_{0}\right\} \\
\theta_{1} B_{1,1}=\left(\frac{R \theta_{1}}{\partial \Theta / \partial p}\right) L_{1}\left\{\left(\overrightarrow{\mathrm{V}}_{1} \cdot \nabla\right) \theta_{1}\right\}, \\
\theta_{1} B_{2,2}=\left(\frac{R \theta_{1}}{\partial \Theta / \partial p}\right) L_{1}\left\{\left(\overrightarrow{\mathrm{V}}_{2} \cdot \nabla\right) \theta_{2}\right\}, \\
\theta_{1} B_{1,2}=\left(\frac{R \theta_{1}}{\partial \Theta / \partial p}\right) L_{1}\left\{\left(\overrightarrow{\mathrm{V}}_{1} \cdot \nabla\right) \theta_{2}+\left(\overrightarrow{\mathrm{V}}_{2} \cdot \nabla\right) \theta_{1}\right\}
\end{gathered}
$$

The first five terms on the right-hand side of (10) can be evaluated from the temperature, horizontal velocity, and $\omega$ data at $500 \mathrm{hPa}$. The last term can be estimated as a residual.

\section{Results}

In this section we first discuss the climatology of blocking in the $\mathrm{SH}$ using 25 years of daily data, giving emphasis to seasonal and interannual variations, and their energetics will be considered later.

\subsection{Seasonal and Interannual Variations}

Figure 1 shows the frequency of blocking as a function of longitude for the entire SH, in the ECMWF (Figure 1a), and the NCEP (Figure 1b) data. In Figure 1b the thick line is obtained with method 1 and the thin line with method 2, using ECMWF data. Figure 1a is also obtained with method 2. It can be seen, in both Figures $1 \mathrm{a}$ and $1 \mathrm{~b}$, that the highest frequency of blocking occurs in the Pacific surrounding Australia and New Zealand. The frequency in the Western Hemisphere is, in general, slightly more than in the Eastern Hemisphere. Between $10^{\circ} \mathrm{E}$ and $90^{\circ} \mathrm{E}$ the blocking frequency is almost zero. The frequency values in the ECMWF data are slightly higher than those in the NCEP data. The frequency values obtained with method 1 are much less than those obtained with method 2. This is because of 4 days of minimum duration of blocking adapted in method 1 , while no such minimum duration is used in method 2. Also, in the thick curve (method 1) there is a slight westward shift of the maximum (around $160^{\circ} \mathrm{W}$ ) in comparison with the thin curve. In the ECMWF data (Figure 1a) a weak secondary maximum can be seen around $90^{\circ} \mathrm{W}$. A similar tendency is seen in the NCEP data (thin curve) also.

Hereinafter, the results (except energetics) are presented only for the NCEP data because of their availability for a longer period. Figure 2 shows the monthly variation of the blocking frequency for all the three southern oceans. In view of 

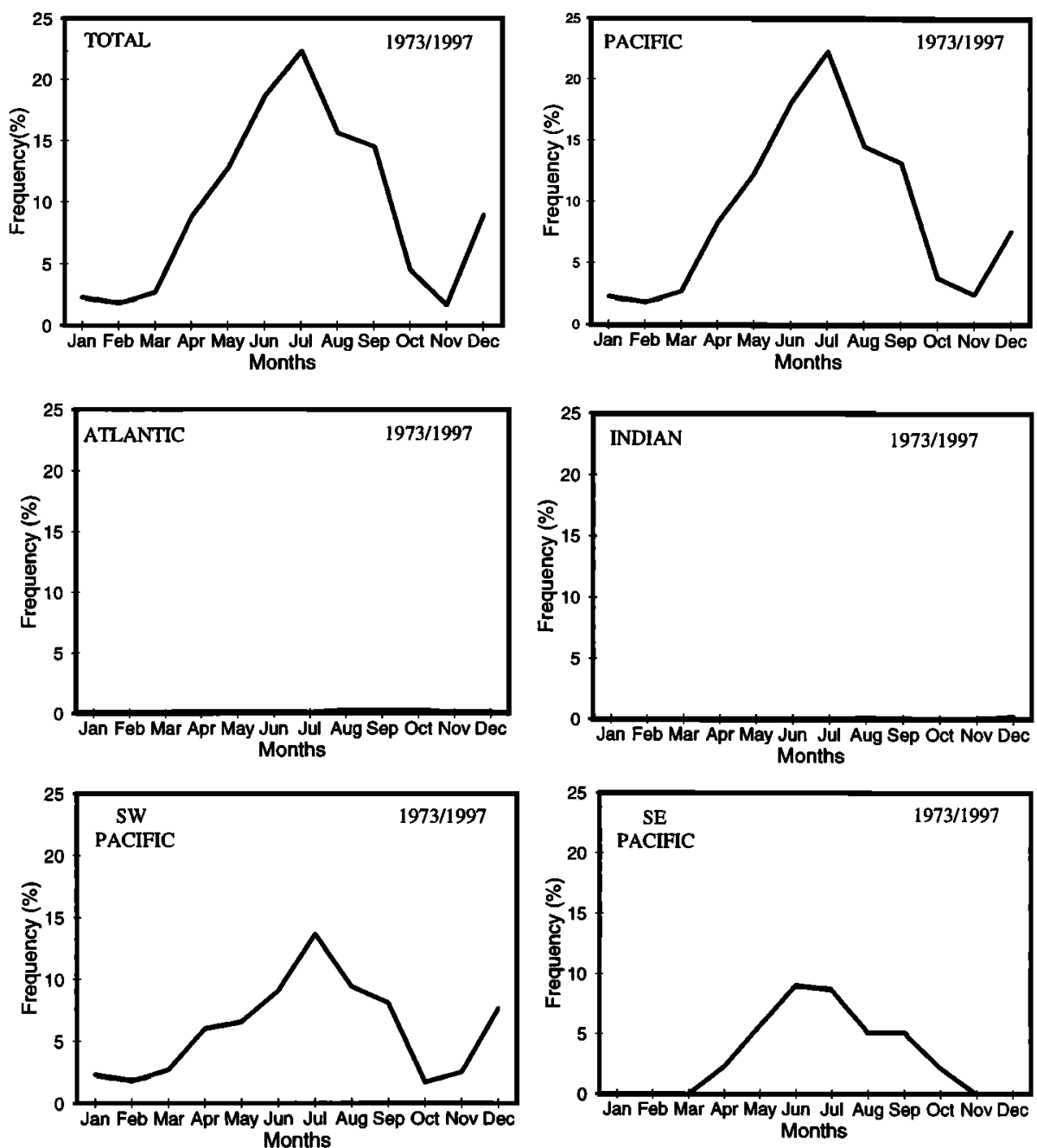

Figure 3. Monthly variation of the frequency of number of days of blocking in NCEP data for the entire SH and for the Pacific, Atlantic, and Indian Oceans and southwest, southeast Pacific separately.

the earlier results of Sinclair [1996] and Renwick [1998], South Pacific is divided into west (west of $120^{\circ} \mathrm{W}$ ) Pacific and east (east $120^{\circ} \mathrm{W}$ ) Pacific. Over the entire SH (without separation) the maximum blocking frequency occurs in winter. There are minima in November and February. It is interesting to note that the blocking frequency increases slightly from November to December. As noted by earlier authors [e.g., Lejenäs, 1984], the blocking frequency is very low over the Atlantic and Indian Oceans. Thus the monthly variation of blocking frequency of the Pacific is reflected in the total for the entire SH. The monthly variation of blocking frequency in the west Pacific is, in general, more than that in east Pacific. In the east Pacific, although the frequencies are smaller than those of west Pacific, still there are sizeable values from May to September. Thus the eastern Pacific is a new region of blocking, as noted by Rutllant and Fuenzalida [1991], Sinclair [1996], and Renwick [1998].

Figure 3 shows the monthly variation of the frequency of number of blocked days. Unlike in the case of blocks, the blocking days, this figure shows a clear maximum in July for the entire SH and for the southwest Pacific. While in the case of southeast Pacific, the frequency in June and July are almost equal. In the Atlantic and Indian Oceans the frequency of number of blocked days is very small. In the case of southeast and southwest Pacific there is a secondary maximum in April.
As in the case of the number of blocks, the frequency of blocked days increase from November to December except in east Pacific.

Figure 4 shows the interannual variation of the frequency of blocks over the entire $\mathrm{SH}$ and also separately for Atlantic, Indian, southwest, and southeast Pacific Oceans. As noted in Figure 3, the frequency of blocks in the Pacific is much higher compared to the other two oceans. Also, another feature evident in Figure 4 is the large interannual variation over Pacific (both west and east) and over the entire SH. High values of frequency occurred in 1974, 1976, 1978, 1984, 1986, 1991, 1992, and 1996 and low values occurred in 1973, 1975, 1980, 1981, 1985, 1989, 1990, and 1995. Figure 5 shows the interannual variation of the number of blocked days. In this figure, also large interannual variation can be seen. As expected, the interannual variation in the frequency of blocked days (Figure 5) and blocking frequency (Figure 4) are very similar in the total values for the SH. A peak is seen in 1986 in both total and over the Pacific (Figure 5). This peak is due to the large value of blocked days in 1986 over southeast Pacific. The number of blocks over southeast Pacific compared to the southwest Pacific in 1986 are not much higher. This implies that the blocks in 1986 over east Pacific lasted for a long time. In an earlier 

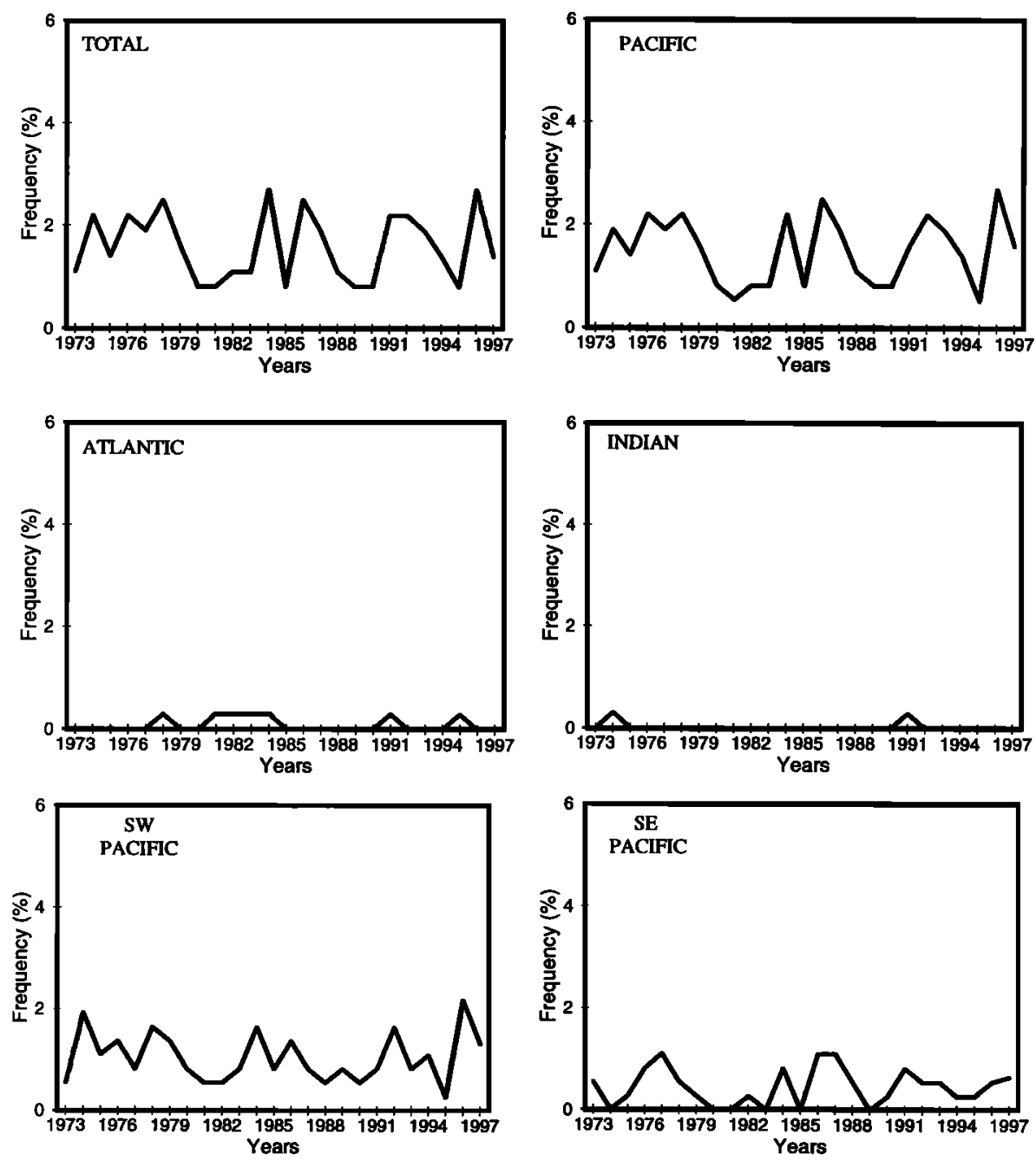

Figure 4. Annual variation of blocking frequency in NCEP data for the entire SH and for the Pacific, Atlantic, and Indian Oceans and southwest, southeast Pacific separately.

study, Marques and Rao [1999] analyzed the case of a longlasting (17 days) blocking event over southeast Pacific in 1986.

\subsection{Connection With ENSO}

Recent studies by Rutllant and Fuenzalida [1991] and Renwick [1998] suggest a connection between ENSO and blocking frequency in the SH. Rutllant and Fuenzalida [1991] report an increase in eastern Pacific blocking during El Niño events. Renwick [1998] noted that over the southeast Pacific at all times of year, El Niño events are associated with increased blocking frequency. Over the southwest Pacific, El Niño is associated with a significant increase in blocking frequency during the period September through February but during the remaining six months with slightly reduced blocking frequency, with net cancellations of the ENSO signal over the years as a whole. Renwick [1998] also noted that ENSO-related variability is not statistically significant over southwest Pacific in March, April, and May (MAM) or December, January, and February (DJF). For the first time in the present study we used 25 years of data, which might provide results that stand the test of statistical significance regarding the connection between blocking and ENSO.

Table 1 gives the linear correlation coefficients between the blocking frequency and the SOI. In column 3 the asterisk is significant with confidence level of $95 \%$ (according to students two-sided $t$ test). It is interesting to note that relatively large CCs (but not significant) are negative, suggesting an increase of blocking during El Niño over the entire SH in autumn and spring and in the southeast Pacific during the spring. The only significant $\mathrm{CC}$ is found for southwest Pacific during the austral autumn season. Thus the present study suggests an increase of blocking in the southwest Pacific in autumn during the El Niño events.

\subsection{Energetics of Contrasting Years}

To see the differences between 3 years of high $(1984,1986$, and 1992) and low (1981, 1989, and 1990) blocking frequency, Figure 6 is prepared. These six years will be analyzed to explore possible causes for high or low blocking frequency. It can be seen in this figure that in the regions of Australia and New Zealand (which is the primary region of blocking in the $\mathrm{SH}$ ) the blocking frequency in the years 1984, 1986, and 1992 is more than double than in the years 1981,1989 , and 1990 . In the secondary region of blocking near the west coast of South America the frequency values are also higher in 1984, 1986, and 1992. Thus the spectacular difference in blocking frequency between the two periods is over the Australia and New Zealand regions. Also, earlier we have seen (Figure 2) that the 

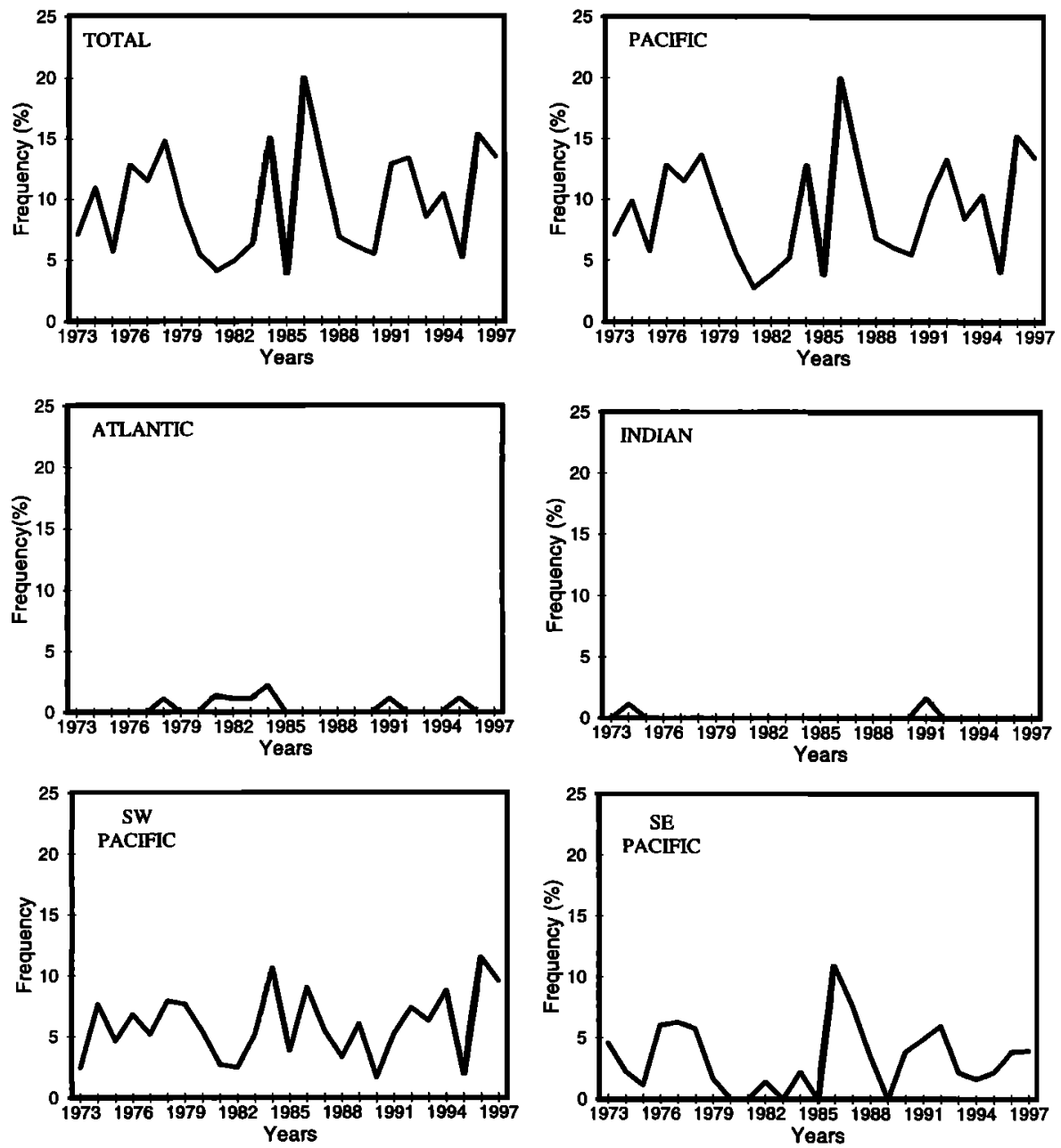

Figure 5. Annual variation of the frequency of number of days of blocking in NCEP data for the entire SH and for the Pacific, Atlantic, and Indian Oceans and southwest, southeast Pacific separately.

austral winter (June, July, and August) is the principal season of blocking over west Pacific. What are the atmospheric characteristics responsible for the differences in blocking frequency between the winter season of these two periods?

To analyze differences in the years of high and low blocking frequency, we calculated energetics for the two sets of 3 years noted earlier, namely, 1984, 1986, and 1992 and 1981, 1989, and 1990 . However, to maximize the differences, we discuss here the energetics of two extreme years, namely, 1984, a year of high frequency of blocking days, and 1990, a year of low frequency (see Figure 5).

Figure 7 shows the first four advection terms on the righthand side of (9) for 1984. It is seen that the values of the interaction between the block component and the seasonal

Table 1. Correlations Coefficients Between the Southern Oscillation Index and Frequency of Blocks for the Entire SH, Southwest Pacific, and Southeast Pacific Separately

\begin{tabular}{lccccc}
\hline \multicolumn{1}{c}{ Region } & DJF & MAM & JJA & SON & ANUAL \\
\hline Southern Hemisphere & 0.12 & -0.30 & -0.002 & -0.31 & -0.1 \\
East Pacific & $\ldots$ & 0.01 & -0.14 & -0.30 & -0.29 \\
West Pacific & 0.12 & $-0.35^{*}$ & -0.01 & 0.01 & 0.1 \\
\hline
\end{tabular}

${ }^{*}$ Significant at $95 \%$ level. flow $\left(\vec{V}_{1} \cdot \vec{A}_{0,1}\right)$ are largest and thus this interaction is important. A region of positive values (generation of intraseasonal kinetic energy) is seen to the south of New Zealand in the region of highest blocking frequency. The maximum value in

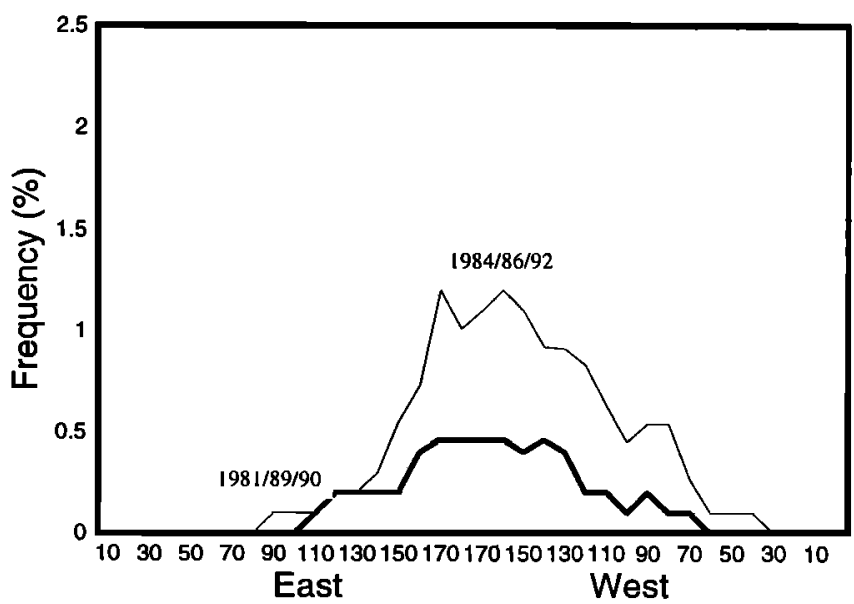

Figure 6. Longitudinal variation of blocking frequency for 3 years maximum (1984/1986/1992) and 3 years minimum (1981/ 1989/1990). 

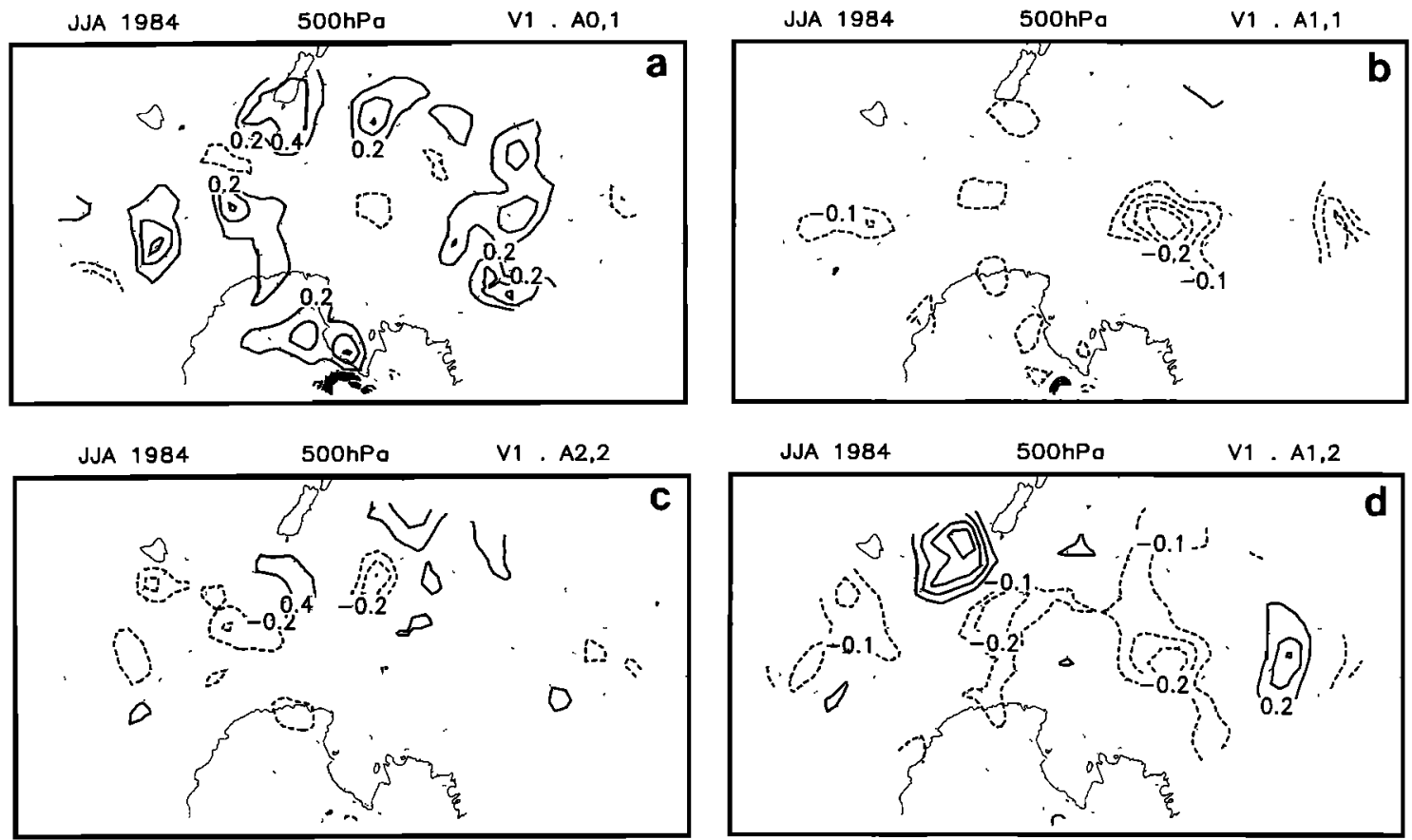

Figure 7. Spatial distribution of the four individual advective terms on the right-hand side of the kinetic energy equation (6) for the winter (1984): (a, c) CI $=0.2 \times 10^{-3} \mathrm{~m}^{2} \mathrm{~s}^{-3},(\mathrm{~b}, \mathrm{~d}) \mathrm{CI}=0.1 \times 10^{-3} \mathrm{~m}^{2} \mathrm{~s}^{-3}$. Zero contours are suppressed.

the region is $0.4 \times 10^{-3} \mathrm{~m}^{2} \mathrm{~s}^{-3}$. Also, note that in Figure $7 \mathrm{~d}$ the term of interaction of the block component and the high frequency $\left(\vec{V}_{1} \cdot \vec{A}_{1,2}\right)$ shows positive values westward of New Zealand, indicating conversion to the block component. Figure 8 shows the values of pressure work term $\left(-\vec{V}_{1} \cdot \nabla \phi_{1}\right)$. The values of this term are, in general, negative over the region to the southwest and southeast of New Zealand. This term partly includes the baroclinic process with conversion between potential and kinetic energy. The maximum negative value indicates that the term redistributes kinetic energy upstream. Figure 9 shows the first four advective terms on the right-hand side of (9) for JJA 1990. A large region of negative values is seen during 1990 in Figure 9a indicating that the intraseasonal component is losing kinetic energy to the seasonal component. In this case, the influence due to self-interaction of synoptic disturbances (Figure 9c) also seems to be important in a region to the south of New Zealand. The term of nonlinear dynamics of blocking disturbance itself (Figure 9b) shows a large negative center (indicating negative advection) to the west of New Zealand. Figure 10 shows the distribution of the pressure work term. Unlike in 1984, mostly positive values are seen to the southeast of New Zealand. A region of strong downstream advection is seen to the southeast of New Zealand. To the west of this region, weak upstream advection is seen.

Thus the terms, which represent the interaction between the block component and the seasonal flow $\left(\vec{V}_{1} \cdot \vec{A}_{0,1}\right)$, the pressure work process $\left(-\vec{V}_{1} \cdot \nabla \phi_{1}\right)$ and the term of direct interaction between the block and the synoptic disturbance $\left(\vec{V}_{1}\right.$. $\vec{A}_{1,2}$ ), show that the atmospheric conditions in 1984 are more favorable for the higher incidence of blocking.

As pointed out by $\operatorname{Mak}$ [1991], the term $\overrightarrow{\mathrm{V}}_{1} \cdot \overrightarrow{\mathrm{A}}_{0,1}$ is very important in the local energetics of blocking. Using the notation of Mak [1991], this term may be written as follows:

$$
\overline{\overrightarrow{\mathrm{V}}_{1} \cdot \overrightarrow{\mathrm{A}}_{0,1}}=-\left(\overrightarrow{\mathrm{V}}_{0} \cdot \nabla\right) \overline{\mathrm{K}_{1}}+\overline{\overrightarrow{\mathrm{E}}_{1}} \cdot \overrightarrow{\mathrm{D}}_{0},
$$

where

$$
\begin{gathered}
\overline{\overrightarrow{\mathrm{E}}_{1}}=\left(\left(\overline{v_{1}^{2}}-\overline{u_{1}^{2}}\right) / 2,-\overline{u_{1} v_{1}}\right) \\
\vec{D}_{0}=\left(D_{\text {stretch }}, D_{\text {sbear }}\right) \\
\vec{D}_{\text {stretch }}=\frac{1}{a \cos \varphi} \frac{\partial u_{0}}{\partial \lambda}-\frac{1}{a} \frac{\partial v_{0}}{\partial \varphi}-\frac{v_{0}}{a} \tan \varphi \\
\vec{D}_{\text {shear }}=\frac{1}{a \cos \varphi} \frac{\partial v_{0}}{\partial \lambda}+\frac{1}{a} \frac{\partial u_{0}}{\partial \varphi}+\frac{u_{0}}{a} \tan \varphi
\end{gathered}
$$

Thus the term $\vec{V}_{1} \cdot \vec{A}_{0,1}$ is a combination of two processes: (1) a redistribution of the kinetic energy of the one component due to the advection by the seasonal component and (2) a generation of kinetic energy by a general barotropic processes given by the term $\vec{E}_{1} \cdot \vec{D}_{0}$. The $\overrightarrow{\mathrm{E}}_{1}$ vector is a measure of the local shape and orientation of the block component of the flow

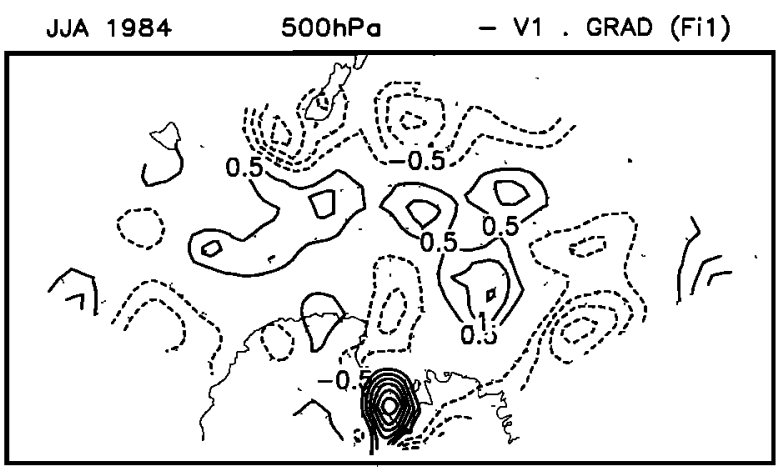

Figure 8. Spatial distribution of the pressure-work term in the kinetic energy equation (9) for the winter (1984): CI = $0.5 \times 10^{-3} \mathrm{~m}^{2} \mathrm{~s}^{-3}$. Zero contours are suppressed. 

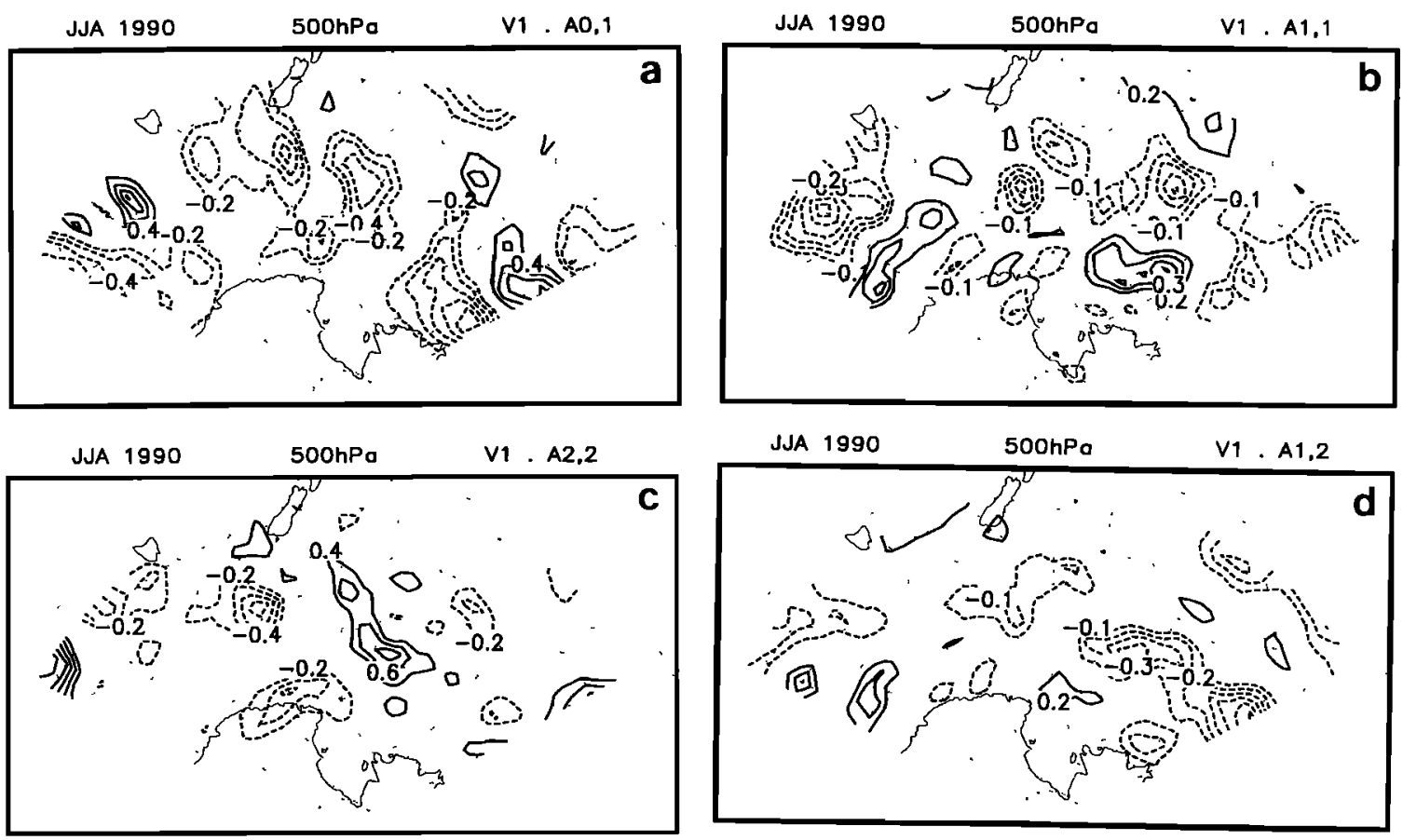

Figure 9. Spatial distribution of the four individual advective terms on the right-hand side of the kinetic energy equation (9) for the winter (1990): $(\mathrm{a}, \mathrm{c}) \mathrm{CI}=0.2 \times 10^{-3} \mathrm{~m}^{2} \mathrm{~s}^{-3}$, (b, d) CI $=0.1 \times 10^{-3} \mathrm{~m}^{2} \mathrm{~s}^{-3}$. Zero contours are suppressed.

and the $\vec{D}_{0}$ vector is a measure of the deformation field of the seasonal flow component. As discussed by Mak and Cai [1989] and $M a k$ [1991], the term $\overrightarrow{\mathrm{E}}_{1} \cdot \overrightarrow{\mathrm{D}}_{0}$ can produce a net increase of the one component kinetic energy in the domain at the expense of the seasonal flow.

Figure 11 shows the term $\overrightarrow{\mathrm{E}}_{1} \cdot \overrightarrow{\mathrm{D}}_{0}$ for JJA 1984 (Figure 11a) and for JJA 1990 (Figure 11b). A large region of positive values is seen (maximum $3 \times 10^{-4} \mathrm{~m}^{2} \mathrm{~s}^{-3}$ ) to the southwest, south, and southeast of New Zealand. While during 1990, although positive values are seen over a small region to the south of New Zealand, their magnitudes are much less in 1990 than in 1984. In other words, the orientation of $\vec{E}_{1}$ and $\vec{D}_{0}$

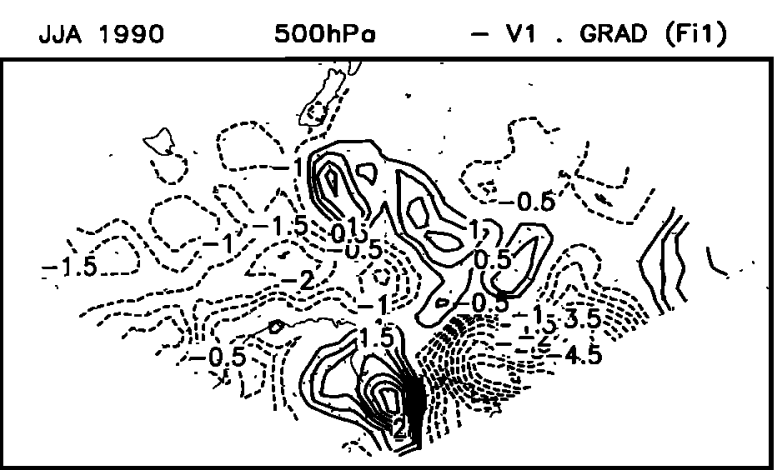

Figure 10. Spatial distribution of the pressure-work term in the kinetic energy equation (6) for winter (1990): CI $=0.5 \times$ $10^{-3} \mathrm{~m}^{2} \mathrm{~s}^{-3}$. Zero contours are suppressed.
E1.Do
$(7-61)$
1984
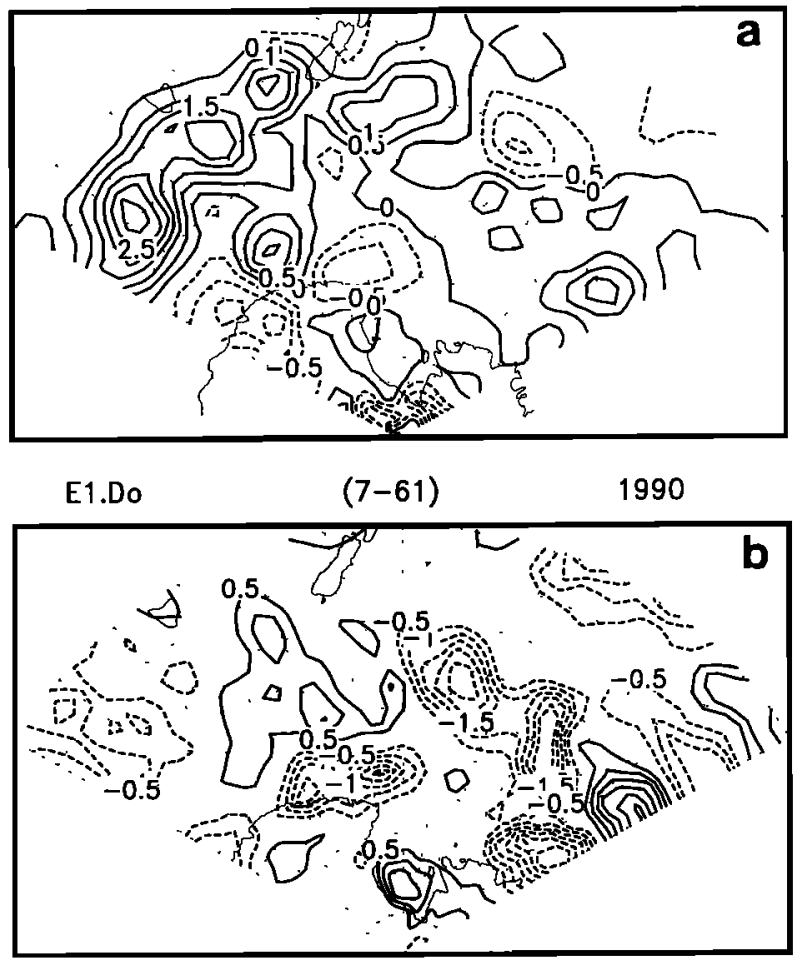

Figure 11. Spatial distribution of $\vec{E}_{1} \cdot \vec{D}_{0}$ vectors, for the winter (a) 1984 , (b) $1990 \mathrm{CI}=0.5 \times 10^{-4} \mathrm{~m}^{2} \mathrm{~s}^{-3}$. Zero contours are suppressed. 
vectors is such that the block component extracts kinetic energy more in 1984 than in 1990 . This seems to favor higher incidence of blocking in 1984 than in 1990.

Figure 12 shows the terms $\theta_{1} \cdot B_{0,1}, \theta_{1} \cdot B_{2,2}, \theta_{1} \cdot B_{1,1}$, and $\theta_{1} \cdot B_{1,2}$ for JJA 1984 . In these figures the values are generally very small, or zero near the region of highest blocking near New Zealand. In Figure 12a, positive values, indicating gain of potential energy by the intraseasonal component at the expense of seasonal mean baroclinic field, are seen to the south of New Zealand near Antarctica. Farther south of this region, negative values are seen. Figure 12 b shows mostly negative values, indicating that synoptic disturbances are gaining potential energy from the block disturbance. The nonlinear term $\theta_{1} \cdot B_{1,1}$ (Figure 12c) is generally small except to the southeast of New Zealand, where negative values are seen, and the term $\theta_{1} \cdot B_{1,2}$ (Figure 12d) is also small. Figure 12e shows the distribution of the conversion rate between kinetic energy
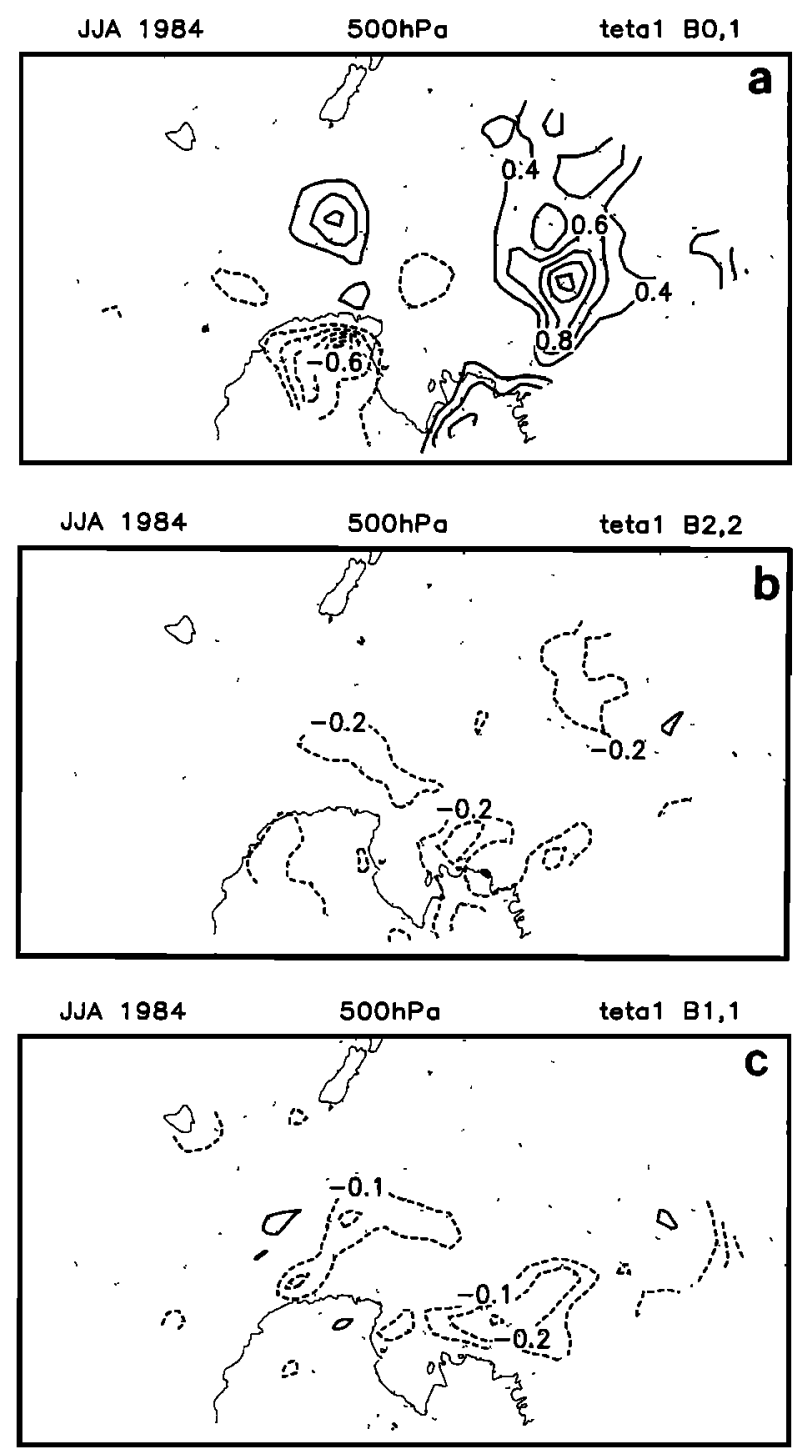

Figure 12. Spatial distribution of the four individual advective terms (Figures 12a-12d) and fifth term (Figure 12e) on the right-hand side of the available potential energy equation (7) for the winter (1984): $(\mathrm{a}, \mathrm{b}, \mathrm{e}) \mathrm{CI}=0.2 \times 10^{-3} \mathrm{~m}^{2} \mathrm{~s}^{-3},(\mathrm{c}, \mathrm{d})$ $\mathrm{CI}=0.1 \times 10^{-3} \mathrm{~m}^{2} \mathrm{~s}^{-3}$. Zero contours are suppressed.
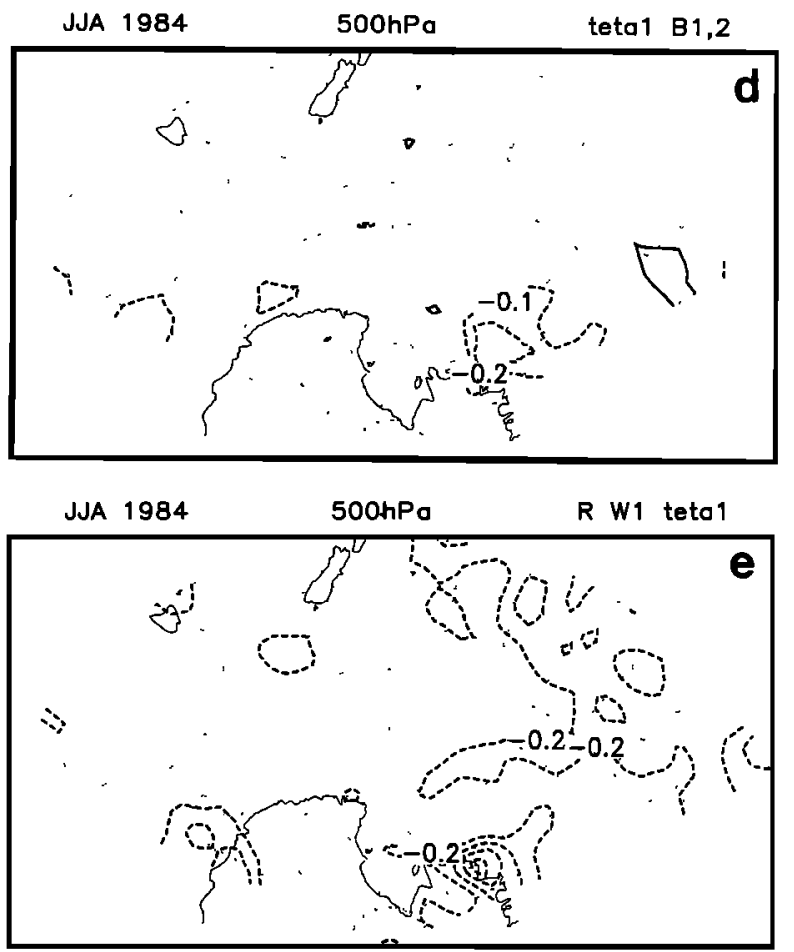

Figure 12. (continued)

and potential energy of the one component $\left(R \omega_{1} \theta_{1}\right)$. Small negative values indicating conversion of potential energy into kinetic energy are seen to the southwest of New Zealand.

Figure 13 shows the terms of potential energy for JJA 1990. In Figure 13a the distribution of the term $\theta_{1} \cdot B_{0,1}$ is shown. Large positive values indicating gain of potential energy by the block disturbance at the expense of the seasonal mean baroclinic field are seen in a region to the southwest of New Zealand. Comparing Figures 12a and 13a, it can be seen that in JJA 1990 the values are larger, indicating higher potential energy gain. Figure 13b shows, again, negative values to the south of New Zealand, indicating that synoptic disturbances are gaining potential energy from the blocking disturbance. Thus the terms $\theta_{1} \cdot B_{0,1}$ and $\theta_{1} \cdot B_{2,2}$ partially compensate one another. Figure $13 \mathrm{c}$ shows mostly negative values except in a small strip to the southeast of New Zealand. In Figure 13d the values of $\theta_{1} \cdot B_{1,2}$ are generally small. Figure $13 \mathrm{e}$ shows the distribution of the conversion rate between kinetic and potential energies. Negative values are seen in this figure, indicating a conversion of potential energy into kinetic energy. Although the values in Figure 13e are higher than those in Figure 12e even near New Zealand, this gain of kinetic energy in 1990 is largely compensated by negative values seen in Figure 9a. This explains, at least partially, the lower frequency of blocking in 1990.

\section{Summary and Conclusions}

In the present investigation, seasonal and interannual variations of blocking in the Southern Hemisphere are studied. Two data sources, namely, 25 years (1973-1997) of NCEP and 14 years (1980-1993) of ECMWF are used. There are two regions of high blocking frequency in the South Pacific, one in southwest Pacific and the other in southeast Pacific. The blocking frequency is higher over southwest Pacific. Blocking occurs 
over the Atlantic and Indian Oceans with much less frequency. Monthly variation of blocking frequency shows that the highest frequency over southwest Pacific occurs in July with secondary peaks in April and September. In the case of southeast Pacific, blocking occurs mainly in the winter months. Large interannual variations of blocking frequency are noted both in southeast and southwest Pacific Oceans. To find a possible connection between the interannual variation of blocking frequency and the Southern Oscillation Index, correlation coefficients are calculated between these two quantities. This showed that a significant negative correlation is found for the austral autumn seasons over southwest Pacific, suggesting higher blocking frequency in El Niño years. Over southeast Pacific, a high negative correlation (not significant) is found for the austral spring season.

Next, the possible causes for the interannual variations are explored by the calculation of energetics for three high and three low years of blocking. Although energetics are calculated

JJA 1990
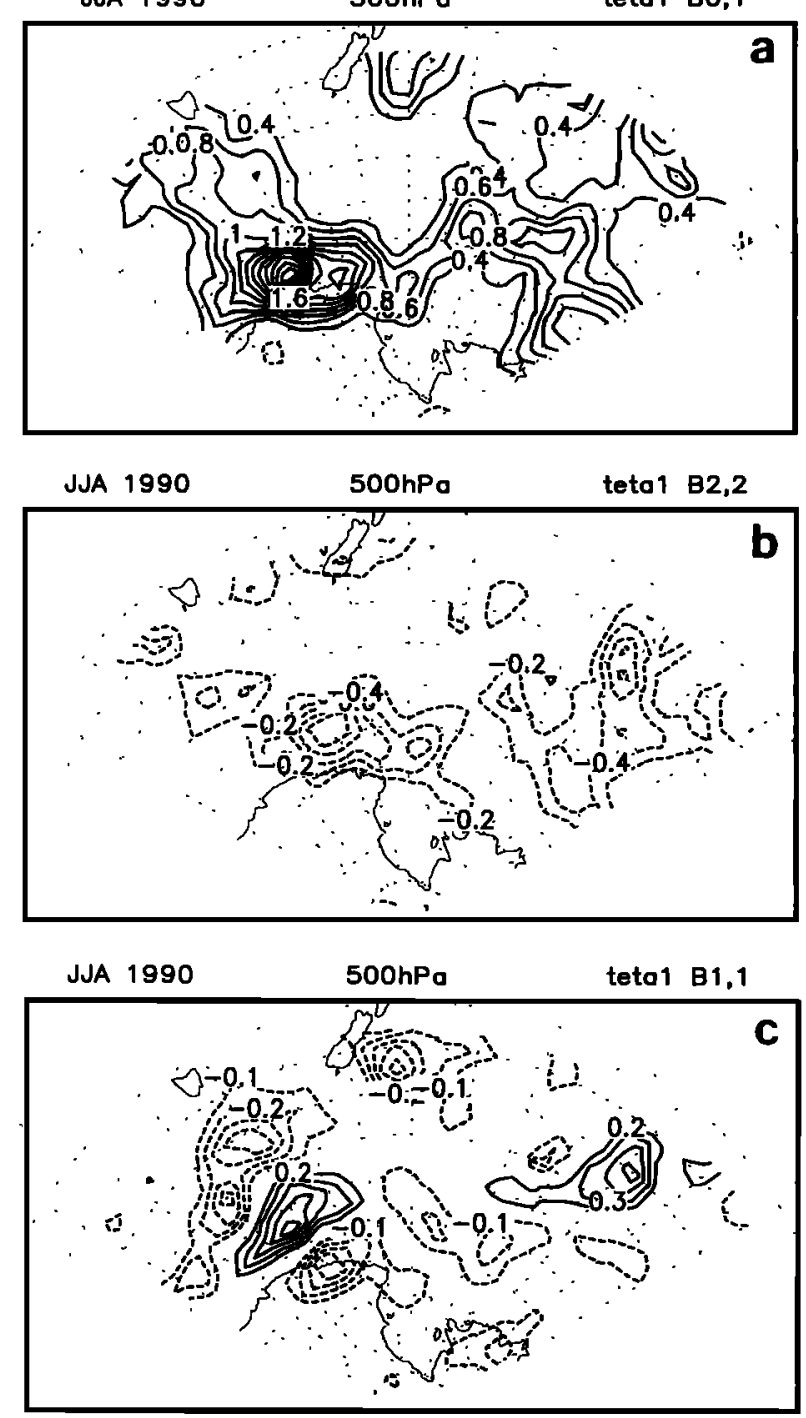

Figure 13. Spatial distribution of the four individual advective terms (Figures 13a-13d) and fifth term (Figure 13e) on the right-hand side of the available potential energy equation (7) for the winter (1990): $(a, b, e) C I=0.2 \times 10^{-3} \mathrm{~m}^{2} \mathrm{~s}^{-3},(\mathrm{c}, \mathrm{d})$ $\mathrm{CI}=0.1 \times 10^{-3} \mathrm{~m}^{2} \mathrm{~s}^{-3}$. Zero contours are suppressed.
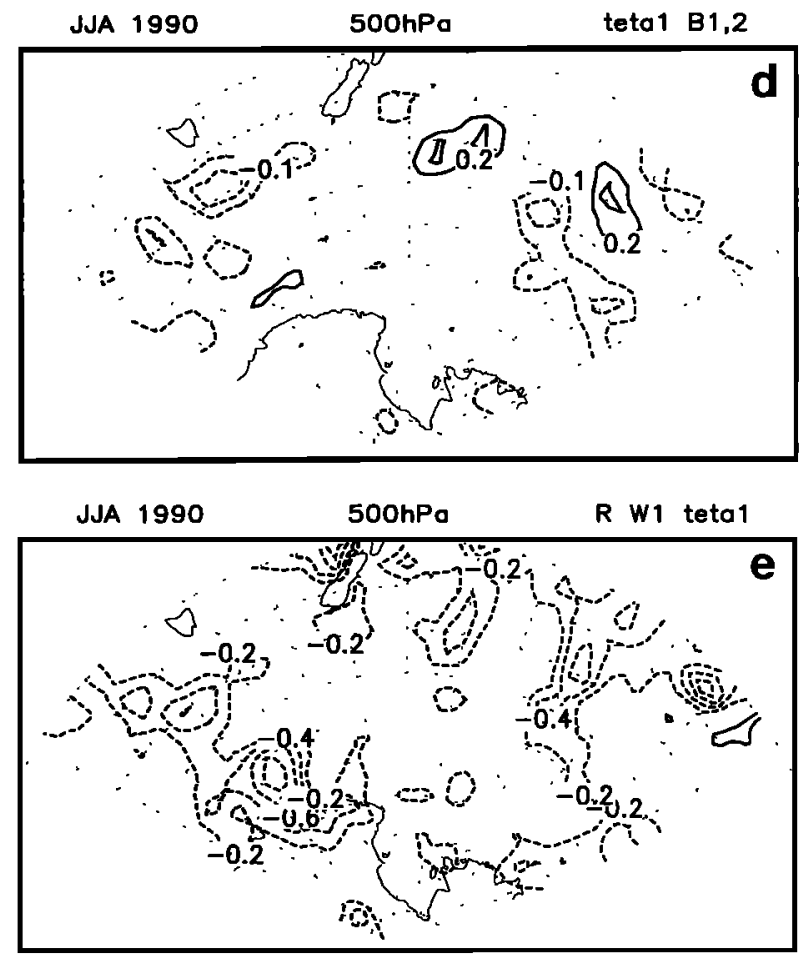

Figure 13. (continued)

for all the six years, to maximize the differences, two extreme years of blocking frequency, the highest (1984) and the lowest (1990), are considered. It is found that the principal term in the local energetics, the interaction between the blocking component and the seasonal component shows large differences between 1984 and 1990. As suggested by Mak [1991], this term is further divided into the dot product of two vectors, one representing the local shape and orientation of the block component of the flow and the other representing the deformation field of the seasonal flow. It is noted that the orientation of these vectors is such that the kinetic energy conversion of the intraseasonal component from the seasonal deformation field is higher in 1984 than in $\mathbf{1 9 9 0}$. Thus it can be concluded that the seasonal mean circulation is favorable for the occurrence of higher blocking frequency in 1984 than in 1990.

Acknowledgments. This work formed part of the Ph.D. thesis of the first author and was done primarily at the Centro de Previsāo de Tempo e Estudos Climáticos, CPTEC. Thanks are due to Carlos A. Nobre for the facilities and for his interest in this work. Thanks are also due to two official reviewers for their useful comments.

\section{References}

D'Andrea, F., et al., Northern Hemisphere atmospheric blocking as simulated by 15 atmospheric general circulation models in the period 1979-1988, Clim. Dyn., 14, 385-407, 1998.

Baines, P. G., A survey of blocking mechanisms with application to the Australian region, Aust. Meteorol. Mag., 31, 27-36, 1983.

Bengtsson, L., Advances and prospects in numerical weather prediction, Q. J. R. Meteorol. Soc., 117, 855-902, 1991.

Berbery, E. H., and M. N. Núñez, An observational and numerical study of blocking episodes near South America, J. Clim., 2, 1352$1361,1989$.

Chen, W. Y., and H. M. Van den Dool, Asymmetric impact of tropical SST anomalies on atmospheric internal variability over the North Pacific, J. Atmos. Sci., 54, 725-740, 1997. 
Coughlan, M. J., A comparative climatology of blocking in the two hemispheres, Aust. Meteorol. Mag., 31, 3-31, 1983.

Dole, R. M., Life cycles of persistent anomalies, part I, Evolution of $500 \mathrm{mb}$ height fields, Mon. Weather Rev., 117, 177-211, 1989.

Elliot, R. D., and T. B. Smith, A study of the effects of large blocking highs on the general circulation in the Northern Hemisphere westerlies, J. Meteorol., 6, 67-85, 1949.

Kalnay-Rivas, E., and L. O. Merkine, A simple mechanism for blocking, J. Atmos. Sci., 28, 2077-2091, 1981.

Kalnay, E., et al., The NCEP/NCAR 40 year reanalysis project, Bull. Am. Meteorol. Soc., 77, 437-471, 1996.

Lejenäs, H., Characteristics of Southern Hemisphere blocking as determined from a long time series of observational data, Q. $J$. $R$. Meteorol. Soc., 110, 967-979, 1984.

Lejenäs, H., and R. A. Madden, Travelling planetary-scale waves and blocking, Mon. Weather Rev., 120, 2821-2830, 1992.

Lejenäs, H., and H. Okland, Characteristics of Northern Hemisphere blocking as determined from long time series of observational data, Tellus, Ser. A, 35, 350-362, 1983.

Mak, M., Dynamics of an atmospheric blocking as deduced from its local energetics, Q. J. R. Meteorol. Soc., 117, 477-493, 1991.

Mak, M., and M. Cai, Local barotropic instability, J. Atmos. Sci., 46 , 3289-3311, 1989.

Marques, R. F. C., and V. B. Rao, A diagnosis of a long-lasting blocking event over the Southeast Pacific Ocean, Mon. Weather Rev. 127, 1761-1776, 1999.

Namias, J., Persistence of flow patterns over North America and adjacent ocean sectors, Mon. Weather Rev., 114, 1368-1383, 1986.

Renwick, J. A., ENSO-related variability in the frequency of South Pacific blocking, Mon. Weather Rev., 126, 3117-3123, 1998.

Renwick, J. A., and J. M. Wallace, Relationships between North Pacific wintertime blocking, El Niño and PNA pattern, Mon. Weather Rev., 124, 2071-2076, 1996.

Rex, D. F., Blocking action in the middle troposphere and its effects upon regional climate, I, An aerological study of blocking action, Tellus, 2, 196-211, 1950a.

Rex, D. F., Blocking action in the middle troposhere and its effects upon regional climate, II, The climatology of blocking action, Tellus, 2, 275-301, 1950b.

Ropelewski, C. F., and P. D. Jones, An extension of the Tahiti-Darwin Southern Oscillation Index, Mon. Weather Rev., 115, 2161-2165, 1987.

Rutllant, J., and H. Fuenzalida, Synoptic aspects of the central Chile rainfall variability associated with the Southern Oscillation, Int J. Climatol., 11, 63-76, 1991.

Shutts, G. J., The propagation of eddies in diffluent jet streams: Eddy vorticity forcing of blocking flow fields, Q.J.R. Meteorol. Soc., 109, 737-761, 1983.

Sinclair, M. R., A climatology of anticyclones and blocking for the Southern Hemisphere, Mon. Weather Rev., 124, 245-263, 1996.

Taljaard, J. J., Synoptic meteorology of the Southern Hemisphere, in Meteorology of the Southern Hemisphere, Meteorol. Monogr. Ser., vol. 35, pp. 139-211, Am. Meteorol. Soc., Boston, Mass., 1972.

Tibaldi, S., and F. Molteni, On the operational predictability of blocking, Tellus, Ser. A, 42, 343-365, 1990.

Tibaldi, S., E. Tosi, A. Navarra, and L. Pedulli, Northern and Southern Hemisphere seasonal variability of blocking frequency and predictability, Mon. Weather Rev., 122, 1971-2003, 1994.

Treidl, R. A., E. C. Binch, and P. Sajecki, Blocking action in the Northern Hemisphere: A climatological study, Atmos. Ocean, 19, $1-23,1981$.

Trenberth, K. E., Na assessment of the impact of transient eddies on the zonal flow during a blocking episode using localized EliassenPalm flux diagnostics, J. Atmos. Sci., 43, 2070-2087, 1986.

Trenberth, K. E., and K. C. Mo, Blocking in the Southern Hemisphere, Mon. Weather Rev., 113, 3-21, 1985.

Trenberth, K. E., and J. G. Olson, Na evaluation and intercomparison of global analyses from National Meteorological Center and the European Center for Medium-Range Weather Forecasts, Bull. Am. Meteorol. Soc., 69, 1047-1057, 1988.

van Loon, H., Blocking action in the Southern Hemisphere, part I, Notos, 5, 171-175, 1956.

von Storch, H., A statistical comparison with observations of control and El Niño simulations using the NCAR CCM, Beitr. Phys. Atmos. 60, 464-477, 1987.

Wright, A. D., Blocking action in the Australian region, Tech. Rep. 10, 29 pp., Dep. of Sci., Bur. of Meteorol., Canberra, Australia, 1974.

R. de Fátima Cruz Marques and V. Brahmananda Rao, Instituto Nacional de Pesquisas Espaciais (INPE), C. P. 515, 12201-970, São José dos Campos, São Paulo, Brazil. (marques@met.inpe.br)

(Received January 27, 1999; revised June 4, 1999; accepted September 28, 1999.) 